\title{
Relationship between Natural Activators of Peroxisome Proliferator Activated Receptors (PPARs) and Endothelial Dysfunction in Patients with Peripheral and Coronary Artery Disease
}

\author{
Mohamed S. Abou-Taleb ${ }^{*}$, Nagwa M. Assem ${ }^{1}$, Kamal M. Ahmed ${ }^{2}$ \\ ${ }^{1}$ Biochemistry Department, Medical Research Institute (MRI), Alexandria University, Egypt. \\ ${ }^{2}$ Cardiology Unit, Medical Research Institute (MRI), Alexandria University, Egypt. \\ *Corresponding Author \\ Mohamed S. Abou-Taleb \\ Department of Biochemistry, Medical Research Institute, \\ Alexandria University, Egypt. \\ Now: Department of Materials Science, \\ Institute of Graduate Studies and Research, \\ Alexandria University \\ Egypt \\ Email: Mohamed.selim12@alexu.edu.eg_mselim_research@yahoo.com \\ Tel: +201222707520
}

Received:20 January 2021; $\mid$ Revised:30 January 2021; $\mid$ Accepted:24 May 2021

\begin{abstract}
Atherosclerosis is considered as a systemic disease which leads to functional and structural changes in several segments of the arterial system. Morbidity and mortality are mostly caused by Peripheral arterial occlusive disease (PAOD). Vascular endothelium, which is a versatile multifunctional tissue, had synthetic and metabolic properties. Endothelial injury may be responsible, for the initiation of atherosclerosis and vascular lesions which are followed by monocyte infiltration, macrophage differentiation, and migration of smooth muscle cells. von Willebrand factor (vWF), acts as a glycoprotein synthesized mainly by endothelial cells, and is an indicator to endothelial damage. It represents the most sensitive marker of peripheral atherosclerosis. Moreover, intima-media thickness (IMT) increasing is used as a non-invasive of early arterial wall alteration marker and is one method of assessing the development of early atherosclerosis. The Peroxisome proliferator-activated receptors (PPARs) regulate both lipid and lipoprotein metabolism and glucose homeostasis so they influence cellular's proliferation, differentiation and cell apoptotic process. PPAR-alpha activity occurs by leukotriene B4, while, PPAR-gamma activator is the oxidized low-density lipoprotein (ox-LDL). PPAR activation decreases the incidence of cardiovascular disease. Leukotriene B4 (LTB4) causes vascular permeability and attraction and activation of leukocytes. So, Oxidized low-density lipoprotein (ox-LDL) plays a crucial role in the inflammatory process genesis occurring in the atherosclerotic lesion. Increased ox-LDL levels have a direct relation to the acute coronary syndromes severity. The levels of vWF, LTB4 and ox-LDL were measured to find the relationship between these parameters and the severe effects of the disease.
\end{abstract}


Keywords:Atherosclerosis, Peroxisome Proliferator Activated Receptors, von Willebrand factor, Leukotriene $\mathrm{B}_{4}$, Oxidized low density lipoprotein

\section{Introduction}

\subsection{Peripheral and Coronary artery diseases:}

Atherosclerosis is the systemic disease which leads to functional and structural changes in several segments of the arterial system. ${ }^{[1]}$ The Peripheral arterial occlusive disease (PAOD) is considered as the major cause of morbidity and mortality. It is characterized by atherosclerotic lesions in large vessels and disturbances on the micro-circulator level. ${ }^{[2]}$

Its reaction is inflammatory at the wall of vessels in response to dyslipidemia along with endothelial distress including, the inflammatory recruitment of leukocytes with the activation of local vascular cells. Atherosclerotic plaques are asymptomatic, having obstruction affect which causes stable angina. ${ }^{[3]}$

The Artery diseases, markedly atherosclerosis and arteriolosclerosis, are the most lethal diseases in the industrial countries leading to sudden death, myocardial infarction, stroke, kidney failure, and limbs ischemia. ${ }^{[4]}$

\subsection{Endothelium:}

Vascular endothelium tissue is a versatile and multifunctional that had both synthetic and metabolic properties. As a semi-permeable membrane, endothelium controls transferring the both smaller and larger molecules into arterial wall and through walls of capillaries and vessels. ${ }^{[5]}$

In addition to contributing in formation of thrombi, endothelial injury is involved in initiation of atherosclerosis and vascular lesions which are followed by monocyte infiltration, macrophages differentiation and in smooth muscle cells migration. ${ }^{[6,7]}$

\subsubsection{Intima Media Thickness (IMT)}

Measuring of intima media thickness is a noninvolvement marker in detection of early alteration in arterial wall. Both IMT and flow associated dilation (FAD \%) are established markers of early atherosclerosis. ${ }^{[8]}$

No significant influencing was found of current drug treatment on flow associated dilation (FAD \%) and intima-media thickness(IMT) as published by Enderle et al (1998) in the following table: ${ }^{[9]}$

Table 1: influence of current drug treatment on flow associated dilation (FAD \%) and intima-media thickness(IMT)

\begin{tabular}{||l|l|l||}
\hline Variable & FAD $\%$ ( $\mathrm{p}$ value $)$ & IMT(p value) \\
\hline Aspirin & 0.765 & 0.594 \\
\hline Nitrites & 0.131 & 0.166 \\
\hline Ca antagonists & 0.608 & 0.955 \\
\hline$\beta$-Blockers & 0.077 & 0.495 \\
\hline Diuretics & 0.948 & 0.997 \\
\hline Statins & 0.273 & 0.777 \\
\hline
\end{tabular}

\section{3 von Willebrand factor (vWF):}

$\mathrm{vWF}$ is a large, adhesive, multimeric glycoprotein presents in plasma, platelets and subendothelium, which can be synthesized as a precursor consisting of signal peptide, a propeptide (von Willebrand antigen II) and the subunit of vWF. It has two main functions which act as a carrier and stabilizer of factor VIII pro-coagulent protein. ${ }^{[10]}$

\subsection{Peroxisome Proliferator Activated Receptors (PPARS)}

Peroxisome proliferator activated receptors (PPARs) which are called ligand - activated transcription factors, considered as a regulatory substance for lipid and lipoprotein metabolism and for glucose homeostasis, and in influencing the cellular proliferation, differentiation and also apoptosis. Its types are PPAR-alpha, PPAR-beta, 
PPAR-gamma and PPAR-delta. PPAR-alpha which higherly expressed is in liver, muscle and kidney, also expressed in heart tissue, where it stimulates the beta-oxidative degradation of fatty acids. PPARgamma is predominately expression is in intestine and adipose tissue, triggering adipocyte differentiation and promoting lipid storage. ${ }^{[11]}$

\subsection{Leukotriene $\mathrm{B}_{4}\left(\mathrm{LTB}_{4}\right)$}

Compared with plants, animal tissues have limited ability in de-saturating fatty acids. This necessities dietary intake of certain polyunsaturated fatty acids derived ultimately from a plant source. Fatty acids (essential) gives the eicosanoic (C20) fatty acids, such families derives compounds termed eicosanoids. These making prostaglandins (PG), thromboxanes (TX), leukotrienes (LT) and the lipoxins (LX) compounds. ${ }^{[12]}$

The prefix leuko is refering to leukocytes, these cells mainly produce Leukotrienes, and the term triene is referring to the three conjugated double bonds in Leukotrienes chemical structures. LTs are generated enzymatically from arachidonic acid (AA) and are released from the enzymes by phospho- lipase A (PLA) of membrane phospholipids. ${ }^{[13]}$

The Arachidonate and C20 fatty acids have methylene-interrupted bonds giving rise to eicosanoids. Arachidonate, usually derived from the 2-position of phospholipids in the plasma membrane, so that phospholipase $\mathrm{A} 2$ activity, will be the substrate for the synthesis of $\mathrm{PG}_{2}, \mathrm{TX}_{2}, \mathrm{LTB}_{4}$ and $\mathrm{LX}_{4}$ compounds. ${ }^{[14]}$

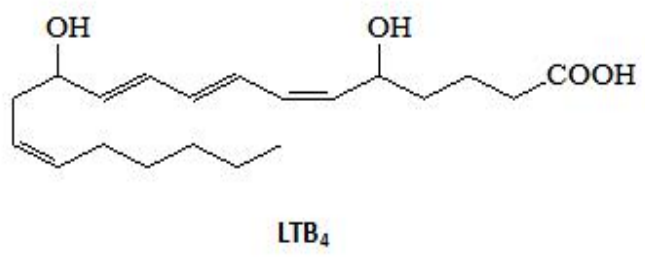

\subsection{Oxidized low- density lipoprotein (ox-LDL)}

Low-density lipoprotein (LDL) Oxidation is the key process in atherogenesis, antioxidant supplements prevent the oxidation of LDL and accordingly, atherogenesis process. ${ }^{[15]}$

Increasing in the oxidative stress in relation of an oxidized LDL (ox-LDL) as a proxy, is associated with oxidant and antioxidant imbalance in biological metabolic syndrome (MS). Concentrations of glucose induce LDL oxidation by MS components development and progression which occurs within insulin resistance process. Also, obesity causes MS origin and is involved in the induction of oxidative stress. ${ }^{[16]}$

\section{Aim of the work}

This study was planned to find the following relationships between:

a-Levels of natural activators of (PPAR-alpha, PPAR-gamma) namely LTB4 and ox-LDL respectively, and the endothelial dysfunction marker vWF.

b-Intima-media thickness (IMT) and the flow mediated dilation (FMD) response in brachial artery in patients with peripheral and coronary artery disease.

\section{Materials and Methods}

\subsection{Materials}

The study includes thirty (30) patients aged from (55-65) years suffering from atherosclerosis. Ten age and sex matched normal healthy persons, were chosen as controls. The patients were taken from those admitted to the clinical cardiology unit of the Medical Research Institute.

\subsection{Methods}

\subsubsection{Clinical investigation}

All atherosclerotic patients were clinically investigated as follows:

1- Standard 12- leads electrocardiogram.

2- M. Mode 2D and Doppler electrocardiographic study.

3- Measurement of Intima-media thickness (IMT) of the carotid artery. ${ }^{[17]}$

4- Measurement of flow mediated and nitroglycerine induced dilation of the brachial artery.[18]

5- Measurement of ankle / brachial systolic pressure index (ABI). ${ }^{[19]}$ 


\subsubsection{Laboratory Investigations}

\subsubsection{Determination of von Willebrand factor (vWF) ${ }^{[20]}$}

\subsection{Principle}

REAADs vWF-Ag is an assay for sandwich ELISA. Antibody capture occur specific for human vWF where coating to micro well polystyrene plates takes place. Dilution of patient plasma is incubated into wells, showing any available vWF: Ag to bind to the anti-human vWF antibody on the microwell surface. The plates are washed removing unbound proteins or other plasma molecules, bound vWF: Ag is quantitated using horse radish peroxidase (HRP) conjugated antihuman vWF detection antibody. Unbound conjugate is removed by washing. A chromogenic substance of tetramethyl benzidine (TMB) and hydrogen peroxide is added to develop a color reaction. The intensity color is measured in optical density (O.D) units with a spectrophotometer at $450 \mathrm{~nm}$.

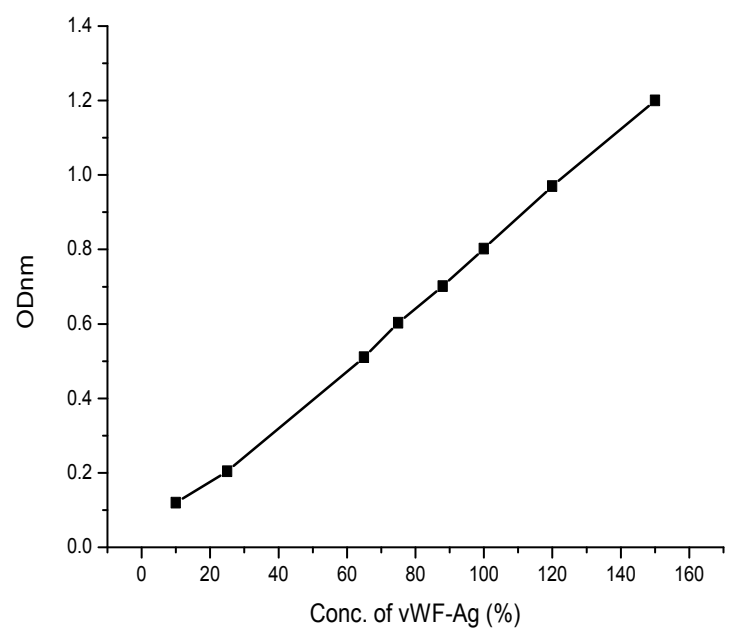

Figure 1: A standard curve for determination of vWF

\subsection{Procedure}

1-Micro well strips were removed.

2-Reference plasma dilution was done.

3-The following was made:

Volume reference plasma Volume sample diluent Reference level

$\begin{array}{rrrr}30 \mu \mathrm{L}+500 \mu \mathrm{L} & = & 150.00 \\ 20 \mu \mathrm{L}+500 \mu \mathrm{L} & = & 100.00 \\ 15 \mu \mathrm{L}+500 \mu \mathrm{L} & = & 75.00 \\ 10 \mu \mathrm{L}+ & 600 \mu \mathrm{L} & = & 50.00 \\ 10 \mu \mathrm{L}+ & 1000 \mu \mathrm{L} & = & 25.00 \\ 10 \mu \mathrm{L}+2000 \mu \mathrm{L} & = & 52.50 \\ 10 \mu \mathrm{L}+4000 \mu \mathrm{L} & = & 6.25\end{array}$

4-1: 25 dilution for sample and control was selected.

5-100ul dilutions was added to micro wells added.
7-Washing with working wash solution was done.

8-Incubation 15 minutes at room temperature was done.

9-100ul HRP conjugated Antibody was added.

10-Incubation for 15 minutes at room temperature was made.

11-Washing 4 times with working wash solution was done.

12-100ul substrate was added to each well.

13-100ul stopping solution was added to each well.

14-Optical density was measured at $450 \mathrm{~nm}$

\subsection{Calculations}

1- Mean O.D. values were calculated duplicate of reference plasma dilutions, control and patient samples.

2- The O. D. was plotted on Y-axis against the corresponding value of reference level (X-axis). 
The curve was linear or plotted. A line was drawn to connect the points.

3- The mean O. D. was used to determine the control and patients relative values from the graph.

4- vWF: Ag percent (\%) was calculated.

\subsubsection{Determination of leukotriene B4 (LTB4)} [21]

\subsection{Principle}

Competitive binding technique in which LTB4 present in a sample competes with a fixed amount of alkaline phosphatase-labeled LTB4 for sites on a rabbit polyclonal antibody. During the incubation, the polyclonal antibody becomes bound to the gout anti-rabbit antibody coated on to the micro plate, following a wash to remove excess conjugate and unbound sample, a substrate solution is added to wells to determine the bound enzyme activity. The color development is stopped and absorbency is read at $405 \mathrm{~nm}$.

\subsection{Procedure}

1-Reagents, Working standards and samples were prepared.

2-Excess micro plate wells strips were removed.

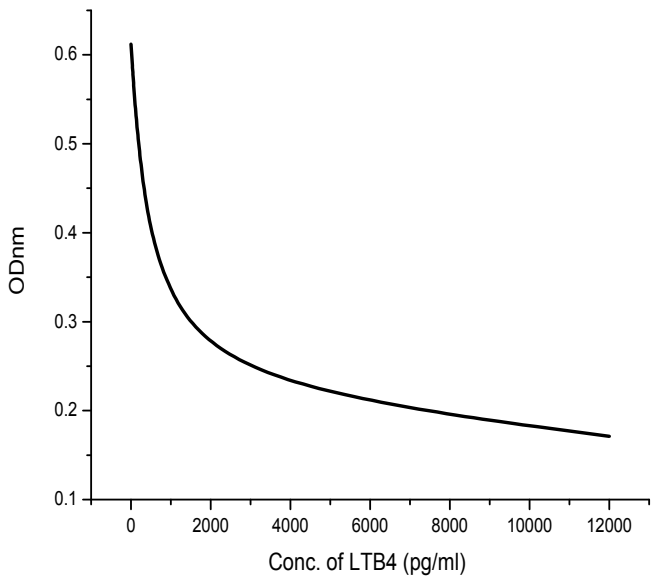

(a)
3-Wells and substrate blank were reserved. 4-150ul assay buffer were added to wells. 5-100ul assay buffer to wells were added.

6-100ul sample to remaining wells were added.

7-50ul LTB4 conjugate was added to wells.

8-50ul LTB4 Antibody solution was added to wells.

9-Washing was made.

10-5ul LTB4 conjugate was added to wells.

11-200ul substrate was added to wells.

12-50ul stop solution was added.

13-Optical density was measured at $405 \mathrm{~nm}$.

\subsection{Calculations}

1- A standard curve was created by plotting the mean absorbance for each standard against concentration.

2- $\% \mathrm{~B} / \mathrm{Bo}$ was calculated by dividing the correction O. D. for each standard or sample by corrected Bo O. D. and multiplying by 100 .

3- Concentration of LTB4 was calculated corresponding to the mean absorbance or $\% \mathrm{~B} / \mathrm{Bo}$ from standard curve.

(Where, TA $=$ Total activity, $\mathbf{B o}=$ Maximum binding, and NSB $=$ Non-specific binding).

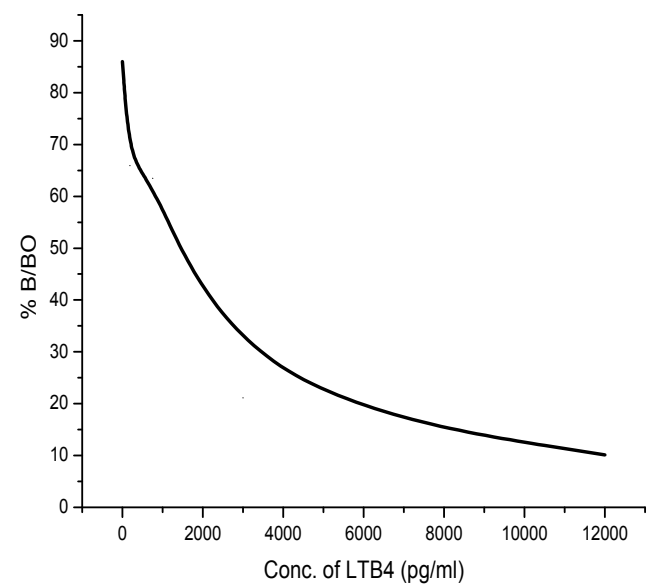

(b)

Figure 2 : (a) A standard curve between optical density and LTB 4 concentration, (b) : A curve between \% B/B $\mathbf{B}_{0}$ and LTB $\mathrm{LT}_{4}$ concentration 


\subsubsection{Determination of oxidized low density lipoprotein (ox-LDL) ${ }^{[22]}$}

\subsection{Principle}

ox- LDL ELISA is a solid phase two site enzyme immunoassay. It is based on the direct sandwich technique in which two monoclonal antibodies are directed against separate antigens determinants on the oxidized apo-lipoprotein molecule. During incubation ox-LDL in the sample reacts with anti-oxidized LDL antibodies bound to titration well. After washing, that removes nonreacted plasma components, a peroxidase conjugated anti- apo-lipoprotein B antibody recognizes the oxidized LDL, bound to the solid phase. After a second incubation and a simple washing step that removes unbound enzyme labeled antibody, the bound conjugate is detected by reaction with 3, 3', 5, 5'-tetra methyl benzidine (TMB). The reaction is stopped by adding acid to give a calorimetric end point that is read spectrophotometically at $450 \mathrm{~nm}$.

\subsection{Procedure}

1-25ul standard, control and samples and 100ul assay buffer were added to anti-oxidized LDL wells.

2-Incubation for 2 hours at room temperature was made.

3-Washing with 350ul wash solution was done.

4-100ul conjugate solution was added.

5-Incubation for 1 hour at room temperature was made.

6-Washing was done.

7-100ul peroxidase substrate was added.

8 -Incubation for 15 minutes was made.

9-50ul stop solution was added.

10-Shaking for 15 seconds was done.

11-Absorbance at $450 \mathrm{~nm}$ was measured.

\subsection{Calculations}

1- The absorbance values were plotted against the ox-LDL concentrations on lin-log paper and a standard curve is constructed.

2- The concentration of controls and unknown samples were read from the standard curve.

3-The concentration on controls and unknown samples were multiplied by dilution factor (e.g. X6561).

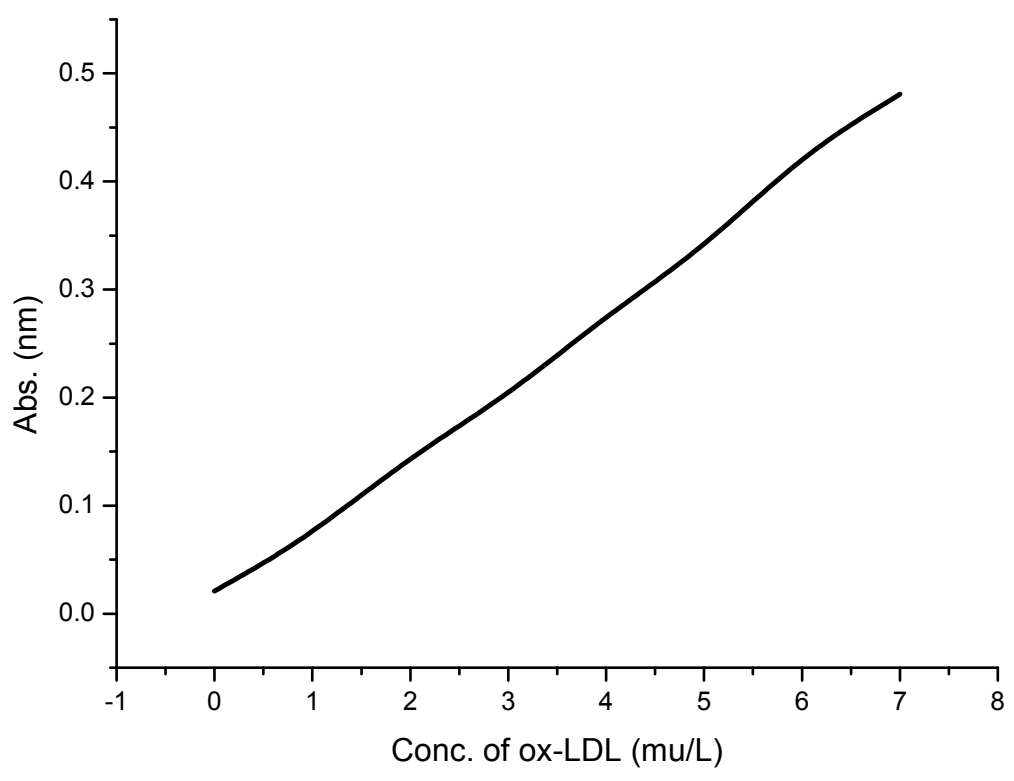

Figure 3: A standard curve of ox-LDL where absorbance is plotted against conc 


\subsubsection{Determination of serum total cholesterol concentration: ${ }^{[23]}$}

\subsection{Principle}

Cholesterol is determined enzymatically using cholesterol esterase and cholesterol oxidase. The created $\mathrm{H} 2 \mathrm{O} 2$ forms a red dyestuff by reacting with 4-amino antipyrene and phenol under the catalytic action of peroxidase. The red quinoneimine dye was measured at $546 \mathrm{~nm}$ by spectrophotometer.

\subsection{Procedure}

1-Prepare three test tubes for blank, standard, and sample, $1 \mathrm{ml}$ of working reagent was put in each one.

2-10ul of dist. $\mathrm{H}_{2} \mathrm{O}$ was added to blank tube, $10 \mathrm{ul}$ of standard solution were added to standard tube, and 10ul of serum were added to sample tube.

3 -All were mixed and incubated for 5 minutes at $37 \mathrm{C}$.

4-The optical density of sample and standard were read against blank at $546 \mathrm{~nm}$.

\subsection{Calculations:}

Conc. of cholesterol $(\mathrm{mg} / \mathrm{dl})=$ OD sample/OD standard X $\mathrm{n}$

$\mathrm{n}=$ standard conc. $=200 \mathrm{mg} / \mathrm{dl}$.

\subsubsection{Determination of serum triglycerides concentrations: ${ }^{[24]}$}

\subsection{Principle}

The enzymatic colorimetric test was done and quinonimine was formed, the colour of quinonimine was measured at $546 \mathrm{~nm}$.

\subsection{Procedure}

1-Prepare three test tubes for blank, standard and sample. $1 \mathrm{ml}$ working solution was put in each one.

2-10ul distilled $\mathrm{H} 2 \mathrm{O}$ were added to blank tube, 10ul of standard solution were added to standard tube, and 10ul serum were added to sample tube.

3-All tubes were mixed and incubated for 5 minutes at $37 \mathrm{C}$.

4-The OD of sample and standard was read against blank at $546 \mathrm{~nm}$.

\subsection{Calculations}

Conc. of serum triglyceride $(\mathrm{mg} / \mathrm{dl})=\mathrm{OD}$ sample/OD standard X n.

$\mathrm{OD}=$ optical density.

$\mathrm{N}=$ standard conc. $=200 \mathrm{mg} / \mathrm{dl}$

\subsubsection{Determination of serum high density lipoprotein - cholesterol (HDL-C): ${ }^{[25]}$}

\subsection{Principle}

The chylomicron, VIDL and LDL are precipitated by addition of phospho tungestic acid and magnesium chloride. After centrifugation, the supernatant fluid contains HDL fraction which was assayed.

\subsection{Procedure}

i. Precipitation:

1-500ul diluted reagent was pipette into centrifuge tube and then $200 \mathrm{ul}$ serum was added.

2-The tubes were mixed, let to stand for 10 minutes at room temperature and centrifugation at $4000 \mathrm{~g}$ was done.

3-After centrifugation, the supernatant (HDLsupernatant), was separated within $1 \mathrm{hr}$, and the cholesterol concentration was determined.

ii. Determination of cholesterol concentration:

1 - In two test tubes for blank and sample, $1 \mathrm{ml}$ cholesterol reagent was put in each one.

2-100 ml dist. H2O was added to blank tube and 100ul HDL-supernatant were added to sample tube.

3-All tubes were mixed and incubated for 10 minutes at 20-25 C.

4-The absorbance of sample was read against blank at $500 \mathrm{~nm}$, the absorbance of sample $=$ A.

\subsection{Calculations}

Conc. of HDL-C = A X $210 \mathrm{mg} / \mathrm{dl}$.

\subsubsection{Estimation of serum low-density lipoprotein cholesterol (LDL-C): ${ }^{[26]}$}

LDL-C concentration is calculated from total cholesterol conc. (TC), HDL cholesterol conc. (HDL-C) and triglycerides conc. (TG) according to the following equation:

Conc. of LDL-C = (TC)-(HDL-C)- $(\mathrm{TG}) / 5$ $\mathrm{mg} / \mathrm{dl}$. 
3.2.2.8 Determination of lipoprotein (a) in serum: [27]

\subsection{Principle}

The wells of polystyrene microplate strips have been coated with mouse monoclonal anti-Lp (a). Incubation with enzyme substrate produced a blue color in the test well, which turned yellow when the reaction was stopped. The amount of color produced was directly proportional to amount of $\mathrm{Lp}$ (a) in the sample or standard solution.

\subsection{Procedure}

1- 10ul specimen, standard or control was added to each well.

2- 100ul sample diluent was added for specimen, standard and controls.

3-Incubation 120 minutes at $37 \mathrm{C}$ was made.

4-Washing 4 times was made.

5-100 ul conjugate solution was added to each well.

6-Incubation 60 minutes at $37 \mathrm{C}$ was made.

7-Washing 4 times was made.

8- 100ul substrate solution was added to each well.

9- Incubation 30 minutes at 20-25 C was made.

$10-100 \mathrm{ml}$ sulphuric acid was added to each well.

11-Absorbance was read at $450 \mathrm{~nm}$.

\subsection{Calculations}

1-A standard curve was constructed by plotting mean absorbance values of $\mathrm{Lp}(\mathrm{a})$ standard solution on $\mathrm{Y}$-axis versus corresponding $\mathrm{Lp}(\mathrm{a})$ conc. on $\mathrm{X}$ axis and a curve was made.

2-Using mean absorbance value for each sample, the conc. of $\mathrm{Lp}(\mathrm{a})$ was obtained.

\section{Results}

The study included 30 patients with PAOD and 10 normal non-smoker subjects as controls. Plasma level of vWF (\%) in the control and patient groups are showed in table (2). It showed that, the plasma levels of vWF ranged between 33.50-69.30 with a mean of $49.310 \pm 11.599$ for control group, while it ranged between 67.20-131.30 with a mean of $98.437 \pm 20.985$ for patients group respectively. This indicating a statistical significant difference between the two studied groups regarding vWF. Plasma level of leukotriene B4 (LTB4) in the control and patient groups are showed in table (2). Levels of LTB4 are ranged between 13.40-31.30 with a mean of $21.360 \pm 6.261$ for the control group, while it ranged between $22.70-52.50$ with a mean of $36.923 \pm 10.171$ for patients group. This indicating a statistical significant difference between the two studied groups regarding LTB4. Plasma level of oxidized low density lipoprotein (ox-LDL) in the control and patient groups are regarding in table (2). Plasma level of ox-LDL ranged between 3.2-8.1 with a mean of $5.02 \pm 1.45$ for control group, while it ranged between 6.6-14.9 with a mean of $9.51 \pm$ 1.91 for patients group. This indicating a statistical significant increase between them regarding oxLDL.The correlation between different studied parameters was significant and positive between $\mathrm{vWF} \&$ LTB4 $(\mathrm{r}=0.59, \mathrm{P}=0.041)$ and $\mathrm{vWF} \&$ oxLDL $(r=0.72, \mathrm{P}=0.021)$ and between LTB4 \& oxLDL $(r=0.68, p=0.032)$. (Table 3$)$ and Figures $(5 a$, $5 \mathrm{~b}$ and $5 \mathrm{c}$ ). Table (5) demonstrated the lipid profile and lipoproteins in the study groups. It showed that, the mean of T.C $(\mathrm{mg} / \mathrm{dl})$ was $258.43 \pm 55.61$ and $185.9 \pm 16.2$ for patients and control groups respectively. The mean of TG $(\mathrm{mg} / \mathrm{dl})$ was 216.38 \pm 70.17 and $106.6 \pm 22.3$ for patients and control group respectively, LDL-C (mg/dl) was $170.11 \pm$ 76.90 and $123.3 \pm 32.3$ for patients and control groups respectively, HDL-C (mg/dl) was $39.29 \pm$ 15.70 and $30.6 \pm 4.32$ for patients and control groups respectively , $\mathrm{Lp}(\mathrm{a})(\mathrm{mg} / \mathrm{dl})$ was $158.8 \pm$ 46.05 and $123.3 \pm 15.9$ for patients and control groups respectively, ox-LDL $(\mathrm{mu} / \mathrm{L})$ was $9.51 \pm$ 1.91 and $5.02 \pm 1.45$ for patients and control groups respectively. This indicating a statistical significant difference between the two study groups regarding lipid profile and lipoproteins. 
Table 2: Plasma levels of von Willbrand factor (vWF) $(\%)$, Leukotriene $\mathrm{B}_{4}\left(\mathrm{LTB}_{4}\right)(\mathrm{pg} / \mathrm{ml})$ and Oxidized low density lipoprotein (ox-LDL) $(\mathrm{mU} / \mathrm{L})$ in the control and patients groups

\begin{tabular}{|c|c|c|c|c|c|c|}
\hline Parameter & \multicolumn{2}{|c|}{ vWF (\%) } & \multicolumn{2}{|c|}{ LTB4 (pg /ml) } & \multicolumn{2}{|c|}{ ox-LDL (mU/L) } \\
\hline No. & $\begin{array}{l}\text { Control } \\
(n=10)\end{array}$ & $\begin{array}{l}\text { Patients } \\
(n=30)\end{array}$ & $\begin{array}{l}\text { Control } \\
(n=10)\end{array}$ & $\begin{array}{c}\text { Patients } \\
(n=30)\end{array}$ & $\begin{array}{l}\text { Control } \\
(n=10)\end{array}$ & $\begin{array}{c}\text { Patients } \\
(n=30)\end{array}$ \\
\hline Range & $\begin{array}{c}33.50- \\
69.30\end{array}$ & $\begin{array}{l}67.20- \\
131.30\end{array}$ & $\begin{array}{l}13.40- \\
31.30\end{array}$ & $\begin{array}{c}22.70- \\
52.50\end{array}$ & $3.2-8.1$ & $6.6-14.9$ \\
\hline Mean & 49.310 & 98.437 & 21.360 & 36.923 & 5.02 & 9.51 \\
\hline SD & 11.599 & 20.985 & 6.261 & 10.171 & 1.45 & 1.91 \\
\hline $\mathbf{t}$ & \multicolumn{2}{|c|}{7.014} & \multicolumn{2}{|c|}{4.537} & \multicolumn{2}{|c|}{6.796} \\
\hline $\mathbf{P}$ & \multicolumn{2}{|c|}{$0.0001^{*}$} & \multicolumn{2}{|c|}{$0.000^{*}$} & \multicolumn{2}{|c|}{$0.0001^{*}$} \\
\hline
\end{tabular}

$* \mathrm{p}<0.05$ is considered significant.

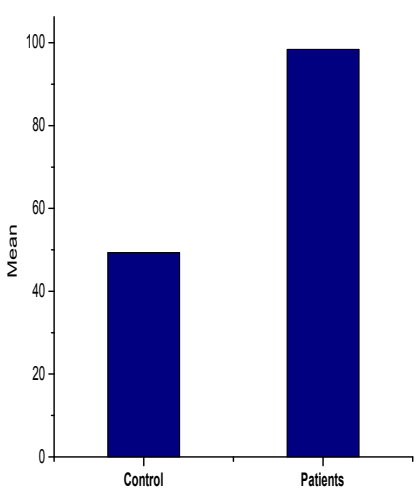

(a)

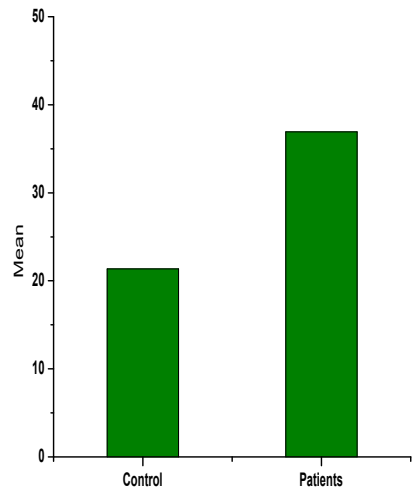

(b)

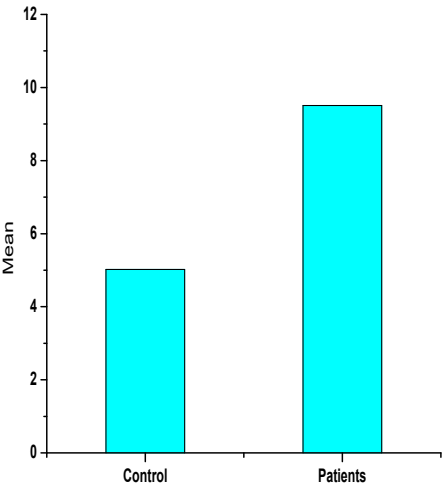

(c)

Figure 4 : (a) Plasma level of vWF (\%), (b) Plasma level of LTB4 (pg/ml), and (c) Plasma level of ox-LDL $(\mathrm{mU} / \mathrm{L})$, in both the control and patient groups 


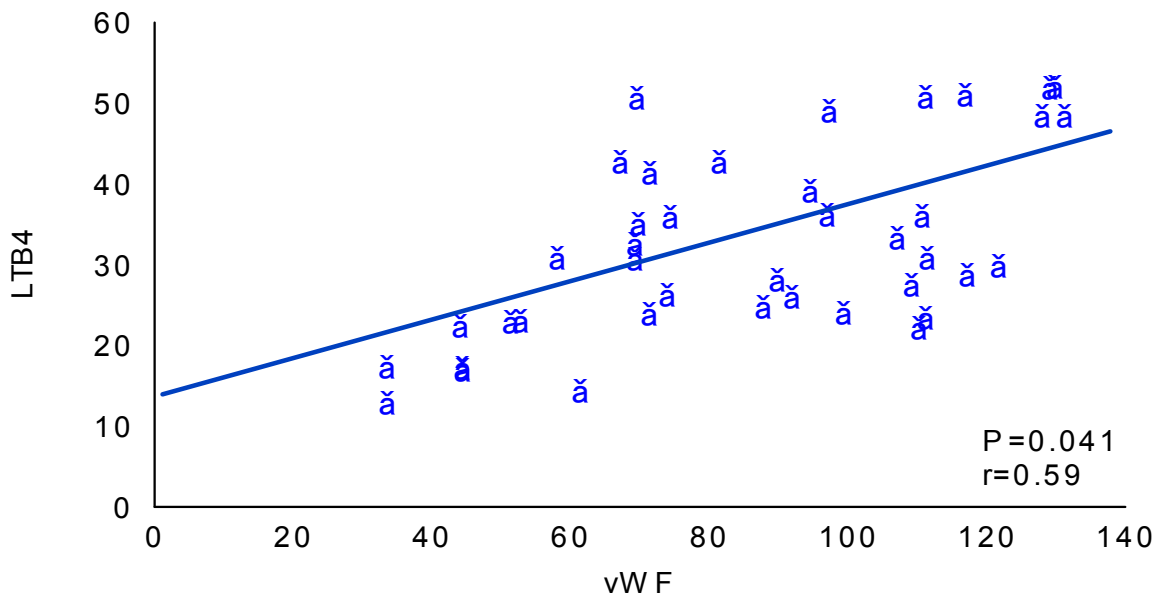

(a)

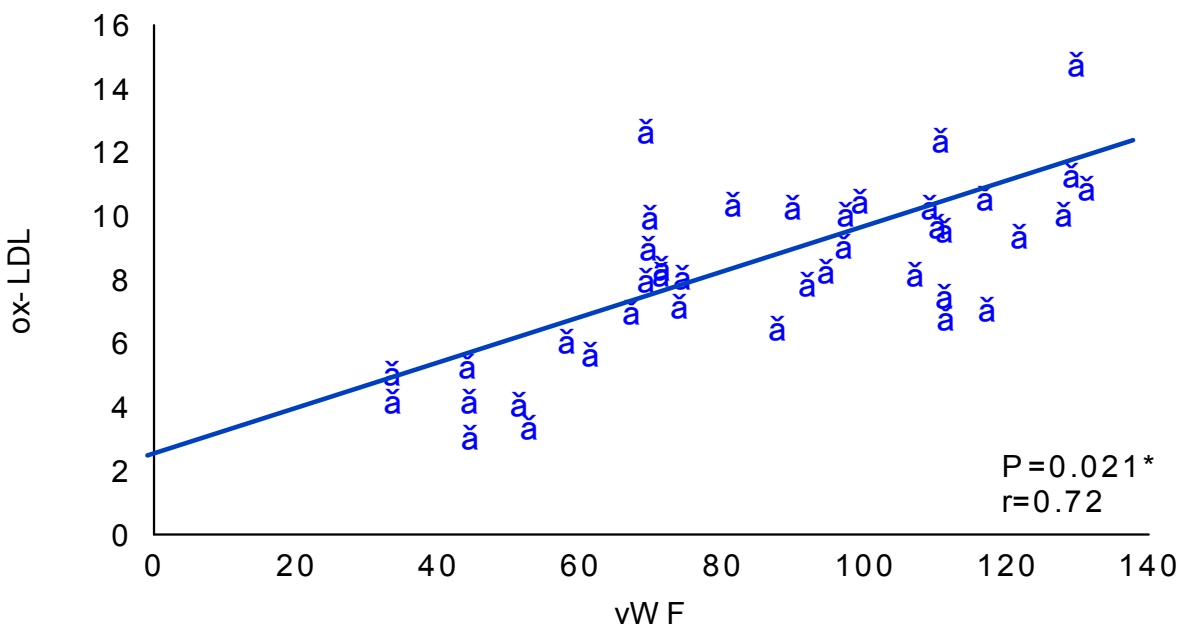

(b)

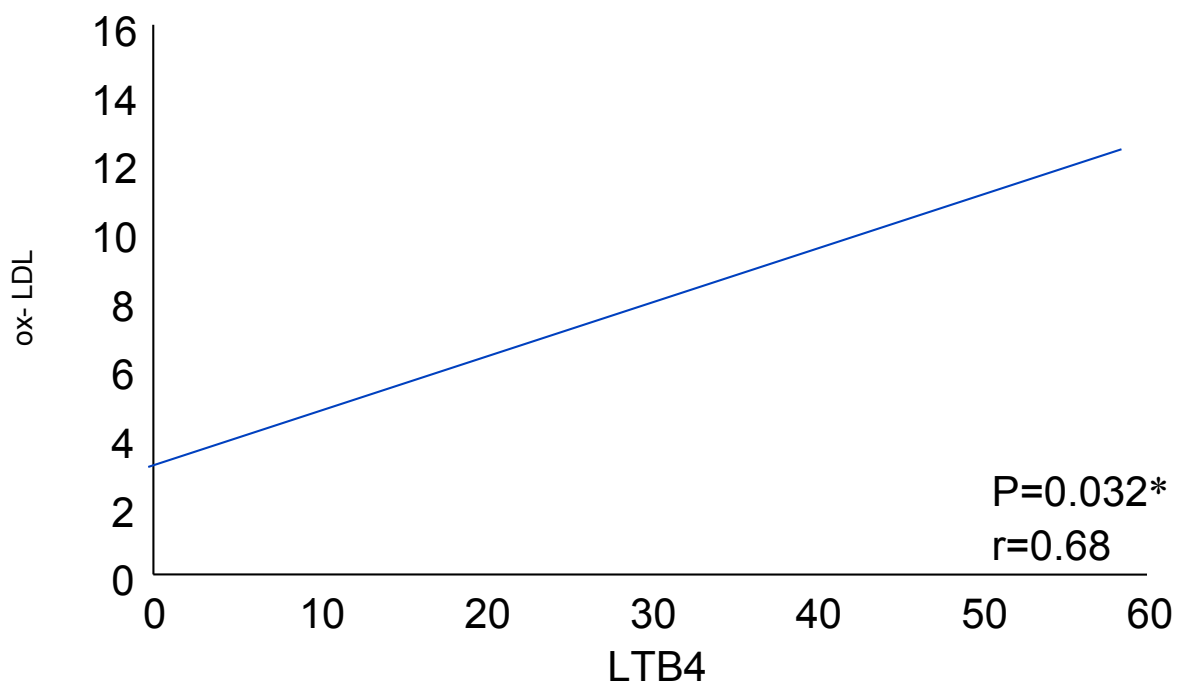

(c)

Figure 5: (a) Correlation between the vWF and LTB4, (b) Correlation between vWF and ox- LDL and (c) Correlation between LTB4 and ox-LDL 
Table 3: Correlation between different studied parameters

\begin{tabular}{|c|c|c|c|c|}
\hline \multirow{2}{*}{ Parameter } & \multicolumn{2}{|c|}{ vWF } & \multicolumn{2}{|c|}{ LTB $_{\mathbf{4}}$} \\
\cline { 2 - 5 } & $\mathbf{r}$ & $\mathbf{p}$ & $\mathbf{r}$ & $\mathbf{p}$ \\
\hline LTB $_{4}$ & 0.59 & $0.041^{*}$ & & $0.032^{*}$ \\
\hline Ox-LDL & 0.72 & $0.021^{*}$ & 0.68 & 0.68 \\
\hline
\end{tabular}

Table 4: Functional arterial properties

\begin{tabular}{||c|c|c|c||}
\hline Properties & $\begin{array}{c}\text { Patients } \\
\mathbf{n}=\mathbf{3 0 "}\end{array}$ & $\begin{array}{c}\text { Control } \\
\text { "n=10" }\end{array}$ & $\mathbf{P}$ \\
\hline Aortic compliance & $0.69 \pm 0.12$ & $0.91 \pm 0.1$ & $0.0001^{*}$ \\
\hline Aortic distensibility & $19.33 \pm 5.87$ & $27.5 \pm 4.21$ & $0.0021^{*}$ \\
\hline Carotid compliance & $0.56 \pm 0.18$ & $0.71 \pm 0.31$ & $0.032^{*}$ \\
\hline Carotid distensibility & $17.84 \pm 4.95$ & $25.3 \pm 5.62$ & $0.0029^{*}$ \\
\hline Femoral compliance & $0.46 \pm 0.15$ & $0.71 \pm 0.31$ & $0.0012^{*}$ \\
\hline Femoral distensibility & $7.5 \pm 2.24$ & $14.0 \pm 4.25$ & $0.0001^{*}$ \\
\hline
\end{tabular}

Table 5: Lipid profile and lipoproteins in the study groups

\begin{tabular}{|c|c|c|c|c|c|}
\hline \multirow[t]{2}{*}{ Variable } & \multicolumn{2}{|c|}{$\begin{array}{l}\text { Patients } \\
" n=30 "\end{array}$} & \multicolumn{2}{|c|}{$\begin{array}{l}\text { Control } \\
" n=10 "\end{array}$} & \multirow[t]{2}{*}{$\mathbf{P}$} \\
\hline & Mean & S.D. & Mean & S.D. & \\
\hline T.C (mg/dl) ${ }^{[23]}$ & 258.43 & 55.61 & 185.9 & 16.2 & $0.001 *$ \\
\hline TG (mg/dl) ${ }^{[24]}$ & 216.38 & 70.17 & 106.6 & 22.3 & $0.003 *$ \\
\hline LDL-C (mg/dl) ${ }^{[26]}$ & 170.11 & 76.90 & 123.3 & 32.3 & $0.021 *$ \\
\hline HDL-C (mg/dl) $)^{[25]}$ & 39.29 & 15.70 & 30.6 & 4.32 & $0.005^{*}$ \\
\hline Lp(a) (mg/dl) $)^{[27]}$ & 158.8 & 46.05 & 123.3 & 15.9 & $0.001 *$ \\
\hline ox-LDL $(\mathrm{mu} / \mathrm{L})^{[22]}$ & 9.51 & 1.91 & 5.02 & 1.45 & $0.0001^{*}$ \\
\hline
\end{tabular}

Where, T.C: Total cholesterol, T.G: Triglycerides, LDL-C: Low density lipoprotein cholesterol, HDL-C: High density lipoprotein cholesterol, Lp (a): Lipoprotein (a) and ox-LDL: oxidized Low density lipoprotein. 


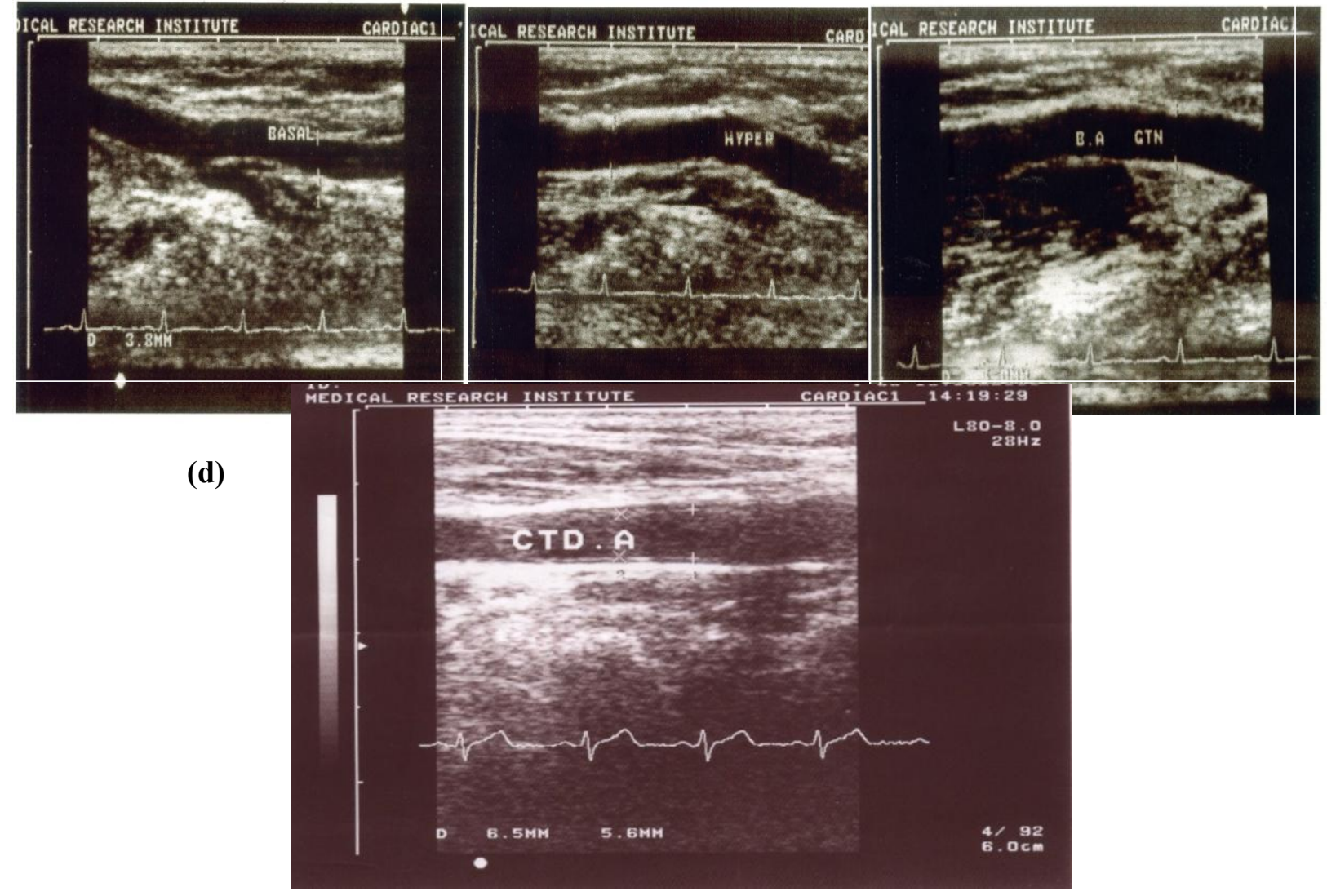

Figure 6: (a): Brachial artery diameter (basal), (b): Brachial artery diameter (flow mediated; FMD), (c): Brachial artery diameter (after glycerol trinitrate; GTN) and (d): Measurement of Intima-Media Thickness of carotid artery

\section{Discussion}

Atherosclerosis is systemic disease. Peripheral arterial occlusive disease is considered as the major cause of mortality and morbidity, endothelial function measures the vascular health which shows impairment in patients with PAOD. ${ }^{[28] ~ I n ~ t h e ~}$ present study, the risk factors of CAD were detected in CAD patients and controls, these risk factors include total cholesterol and triglyceride level, as well as, LDL-C and HDL-C levels.

Endothelial function can be measured by biophysical and biochemical methods. Simon, et al (1999) found that non-invasive high resolution ultrasound is utilized to assess the dilation changes of brachial arteries during reactive hyperemia, in flow mediated dilation (FMD) and after sublingual uptake of glyceryl trinitrate (GTN) have confirmed as surrogate test for endothelial function. ${ }^{\text {[29] }}$

Raised plasma concentration of circulating vWF has an association with endothelial damage and represents the most sensitive marker of peripheral atherosclerosis. ${ }^{[30]}$ The results showed that von Willebrand factor (vWF) showed significant higher values in CAD patients comparing to the control group $(\mathrm{p}<0.05)$.

LTB4 is the major product in the arachidonic acid metabolism which is found via 5-lipoxygenase pathway. LTB4 helps stimulating leukocytes function which includes release of lysosomal enzyme, adhesion and aggregation of poly-morpho nuclear leukocytes. [31] Our results showed that LTB4 was significantly higher in CAD patients as compared to control group $(\mathrm{p}<0.05)$.

Oxidized low density lipoprotein (ox-LDL) has an important role in atherosclerotic plaques genesis. The first stage of the formation of atherosclerotic plaque is involving oxidation of LDL and the subsequent uptake by macrophage. ${ }^{[32]}$ Our results showed that ox-LDL had a significant higher values in CAD patients as compared to control group $\mathrm{p}<0.05$. Wilinink, et al (2000) found that lipoprotein 
(a) causes endothelial dysfunction and also elastic arterial properties alteration. ${ }^{[33]}$

PPAR-alpha activators decrease the inflammatory response in vivo and in vitro. PPARalpha activators undergo their anti-inflammatory action, at least in part by negatively regulating NF$\mathrm{KB}$ transcriptional activity. This anti-inflammatory activity may apply generally to PPAR-family members as PPAR- $\gamma$ has been found to inhibit macrophage activation in vitro. ${ }^{[34]}$ There was a significantly association between the level of $\mathrm{vWF}$ and ABI. Also it was found that there was a strong association between $\mathrm{VWF}$ and angiographic extent of PAOD. ${ }^{[35]}$

\section{Conclusions}

Atherosclerosis is a systemic disease generated which involves arterial structure and function.

That can be detected both biophysically by Flow Mediated Dilation (FMD) and Glyceryl Nitrate (GTN \%) and biochemically (vWF). Aspects of vascular endothelium deteriorate in parallel with disease progression and can be used as diagnostic markers of atherosclerosis. The standard accurate non-invasive methods to assess ankle-brachial index, compliance and distensibility proved to be mostly predictive for the presence of extent of PAOD severity. vWF, LTB4 and ox-LDL are elevated in patients with peripheral and coronary artery diseases, so they can be used as marker of the disease.

\section{Acknowledgement}

I'm thankful greatly with my deepest gratitude to all Professors of Biochemistry and Applied Medical Chemistry Department, Medical Research Institute, Alexandria University for their willingness to donate a lot of their precious time and vast experience and for their meticulous help in this research.

\section{Conflict of Interest}

This research did not receive any specific grant from funding agencies in the public, commercial, or not-for profit sectors.

\section{References}

1 Hirsch AT, Criqui MH, Treat-Jacobson D, Regensteiner JG, Creager MA, Olin JW, Krook SH, Hunninghake DB, Comerota AJ, Walsh ME, McDermott MM, Hiatt WR. Peripheral arterial disease detection, awareness, and treatment in primary care. JAMA 2001; 286(11): 1317-1324 [PMID: 11560536 DOI: 10.1001/jama.286.11.1317]

2 Weiss T, Fischer D, Hausmann D, Weiss C. Endothelial function in patients with peripheral vascular disease: influence of prostaglandin E1. Prostaglandins Leukot Essent Fatty Acids 2002; 67(5): 277-281 [PMID: 12445486 DOI: 10.1054/plef.2002.0429]

3 Faisal H, Hawra A, Ahmed A, Hassan M, Mohamed M, et al. Atherosclerosis: Pathophysiology and Management. The Egyptian Journal of Hospital Medicine 2018; 70: 82-87. [DOI: 10.12816/0042966]

4 Fishbein MC, Fishbein GA. Arteriosclerosis: facts and fancy. Cardiovasc Pathol 2015; 24(6): 335-342 DOI: 10.1016/j.carpath.2015.07.007

5 Pearson JD. Endothelial cell function and thrombosis. Baillieres Clin Haematol 1994; 7(3): 441-452 DOI: 10.1016/s0950$\underline{3536(05) 80092-7}$

6 Ross R. The pathogenesis of atherosclerosis: a perspective for the 1990s. Nature 1993; 362(6423): 801-809 DOI: $\underline{10.1038 / 362801 \mathrm{a} 0}$

7 Fuster V, et al. Atherosclerosis and coronary artery disease Philadelphia USA, LippincottRaven Publisher, 1996. DOI:10.1002/food.19960400439

8 Bots ML, Hofman A, Grobbee DE. Common carotid intima-media thickness and lower extremity arterial atherosclerosis. The Rotterdam Study. Arterioscler Thromb 1994; 14(12): 1885-1891 DOI: 10.1161/01.atv.14.12.1885

9 Enderle MD, Schroeder S, Ossen R, Meisner C, Baumbach A, Haering HU, Karsch KR, Pfohl M. Comparison of peripheral endothelial dysfunction and intimal media thickness in patients with suspected coronary artery disease. Heart 1998; 80(4): 349-354 DOI: $\underline{10.1136 / \mathrm{hrt} .80 .4 .349}$ 
10 Mary LT,Hemostasis and thrombosis.Clin. Hematology (2 $2^{\text {nd }}$ ed) 1993; 15: 288.

11 Delerive P, Fruchart JC, Staels B. Peroxisome proliferator-activated receptors in inflammation control. J Endocrinol 2001; 169(3): 453-459 DOI: $10.1677 /$ joe.0.1690453

12 Fischer S. Dietary polyunsaturated fatty acids and eicosanoid formation in humans. $\boldsymbol{A d \boldsymbol { d }}$ Lipid Res 1989; 23: 169-198 [PMID: 2516986 DOI: $10.1016 / \mathrm{b} 978-0-12-024923-7.50008-\mathrm{x}]$

13 Sasaki F, Yokomizo T. The leukotriene receptors as therapeutic targets of inflammatory diseases. Int Immunol 2019; 31(9): 607-615 DOI: 10.1093/intimm/dxz044

14 Khosla P, Hayes KC. Dietary transmonounsaturated fatty acids negatively impact plasma lipids in humans: critical review of the evidence. J Am Coll Nutr 1996; 15(4): 325339 DOI: $10.1080 / 07315724.1996 .10718607$

15 Terentis AC, Thomas SR, Burr JA, Liebler DC, Stocker R. Vitamin E oxidation in human atherosclerotic lesions. Circ Res 2002; 90(3): 333-339 DOI: $\underline{10.1161 / \mathrm{hh} 0302.104454}$

16 Hurtado-Roca Y, Bueno H, Fernandez-Ortiz A, Ordovas JM, Ibanez B, Fuster V, RodriguezArtalejo F, Laclaustra M. Oxidized LDL Is Associated With Metabolic Syndrome Traits Independently of Central Obesity and Insulin Resistance. Diabetes 2017; 66(2): 474-482 [PMID: 27993926 DOI: 10.2337/db16-0933]

17 Hashimoto M, Eto M, Akishita M, Kozaki K, Ako J, Iijima K, Kim S, Toba K, Yoshizumi M, Ouchi Y. Correlation between flow-mediated vasodilatation of the brachial artery and intima-media thickness in the carotid artery in men. Arterioscler Thromb Vasc Biol 1999; 19(11): 2795-2800 [PMID: 10559028 DOI: 10.1161/01.atv.19.11.2795]

18 Masayoshi H,Masato E, Masahiro,et al. A correlation between FMD vasodilation of brachial artery and IMT in carotid artery in men. Atherosclerosis 1999; 19: 2795-2800. DOI: $10.1161 / 01 . A T V .19 .11 .2795$

19 Papamichael CM, Lekakis JP, Stamatelopoulos KS, Papaioannou TG, Alevizaki MK, Cimponeriu AT, Kanakakis JE, Papapanagiotou A, Kalofoutis AT, Stamatelopoulos SF. Ankle-brachial index as a predictor of the extent of coronary atherosclerosis and cardiovascular events in patients with coronary artery disease. $\boldsymbol{A m} \boldsymbol{J}$ Cardiol 2000; 86(6): 615-618 DOI: 10.1016/s0002-9149(00)01038-9

20 Hoyer LW. The factor VIII complex: structure and function. Blood 1981; 58(1): 1-13 [PMID: 6165414]

21 Ramwell PW. Determination of leukotriene B4. Reprod 1977; 16:70.

22 Steinberg D. Low density lipoprotein oxidation and its pathobiological significance. J Biol Chem 1997; 272(34): 20963-20966 [PMID: 9261091 DOI: $10.1074 / j b c .272 .34 .20963]$

23 Allain CC, Poon LS, Chan CS, Richmond W, $\mathrm{Fu}$ PC. Enzymatic determination of total serum cholesterol. Clin Chem 1974; 20(4): 470-475 [PMID: 4818200]

24 Bucolo G, David H. Quantitative determination of serum triglycerides by the use of enzymes. Clin Chem 1973; 19(5): 476-482 [PMID: 4703655]

25 Gordon T, Castelli WP, Hjortland MC, Kannel WB, Dawber TR. High density lipoprotein as a protective factor against coronary heart disease. The Framingham Study. Am J Med 1977; 62(5): 707-714 [PMID: 193398 DOI: 10.1016/0002-9343(77)90874-9]

26 Assmann G, Jabs HU, Kohnert U, Nolte W, Schriewer H. LDL-cholesterol determination in blood serum following precipitation of LDL with polyvinylsulfate. Clin Chim Acta 1984; 140(1): $\quad 77-83 \quad$ DOI: $\quad 10.1016 / 0009-$ 8981(84)90153-0

27 Alber JJ.Determination of Lp(a) J Lip Res 977; 18: $331-8$

28 Brendle DC, Joseph LJ, Corretti MC, Gardner AW, Katzel LI. Effects of exercise rehabilitation on endothelial reactivity in older patients with peripheral arterial disease. $\mathbf{A m} \boldsymbol{J}$ Cardiol 2001; 87(3): 324-329 DOI: 10.1016/s0002-9149(00)01367-9

29 Simon BC, Noll B, Maisch B. [Endothelial dysfunction--assessment of current status and approaches to therapy]. Herz 1999; 24(1): 6271 DOI: $10.1007 / \mathrm{BF} 03043820$

30 Blann AD,De Romeuf C, et al. Circulating vWF antigen II in atheroscherosis a comparison with vWF and soluble thrombo-modulin. Blood coagul fibrinolysis. 1998; 9(3): 261-6. 
31 Staub NC, Schultz EL, Koike K, Albertine KH. Effect of neutrophil migration induced by leukotriene B4 on protein permeability in sheep lung. Fed Proc 1985; 44(1 Pt 1): 30-35 [PMID: 2981731]

32 Shorchi E, Makiko V, Akira I. Elevated levels of ox-LDL shows a positive relationship with severity of acute and coronary syndromes. Circulation 2001; 103: 1955-60

33 Wilmink HW, de Kleijn MJ, Bots ML, Bak AA, van der Schouw YT, Engelen S, Planellas $\mathrm{J}$, Banga J, Grobbee DE. Lipoprotein (a) is associated with endothelial function in healthy postmenopausal women. Atherosclerosis 2000; 153(1): 249-254 DOI: $10.1016 / \mathrm{s} 0021-$ $\underline{9150(00) 00411-1}$
34 Staels B, Koenig W, Habib A, Merval R, Lebret M, Torra IP, Delerive P, Fadel A, Chinetti G, Fruchart JC, Najib J, Maclouf J, Tedgui A. Activation of human aortic smoothmuscle cells is inhibited by PPARalpha but not by PPARgamma activators. Nature 1998; 393(6687): 790-793 DOI: $\underline{10.1038 / 31701}$

35 Woodburn KR, Lowe GD, Rumley A, Love J, Pollock JG. Relation of haemostatic, fibrinolytic, and rheological variables to the angiographic extent of peripheral arterial occlusive disease. Int Angiol 1995; 14(3): 219225 [PMID: 8919237] 